\title{
RELATIONS BETWEEN THE GENERALIZED BESSEL FUNCTIONS AND THE JANOWSKI CLASS
}

\author{
S. Kanas, S. R. Mondal and A. D. Mohammed
}

Abstract. We are interested in finding the sufficient conditions on $A, B, \lambda, b$ and $c$ which ensure that the generalized Bessel functions $u_{\lambda}:=u_{\lambda, b, c}$ satisfies the subordination $u_{\lambda}(z) \prec$ $(1+A z) /(1+B z)$. Also, conditions for which $u_{\lambda}(z)$ to be Janowski convex, and $z u_{\lambda}^{\prime}(z)$ to be Janowski starlike in the unit disk $\mathbb{D}=\{z \in \mathbb{C}:|z|<1\}$ are obtained.

Mathematics subject classification (2010): 34B30, 33C10, 30C80, 30C45.

Keywords and phrases: Convexity, Janowski convexity, starlike functions, generalized Bessel functions, differential subordination.

\section{REFERENCES}

[1] R. M. Ali, V. Ravichandran and N. Seenivasagan, Sufficient conditions for Janowski starlikeness, Int. J. Math. Math. Sci. 2007, Art. ID 62925, 7 pp.

[2] R. M. Ali, R. ChandrashekAR And V. RAVICHANDRAn, Janowski starlikeness for a class of analytic functions, Appl. Math. Lett. 24, 4 (2011), 501-505.

[3] Á. BARICZ, Geometric properties of generalized Bessel functions, Publ. Math. Debrecen 73, 1-2 (2008), 155-178.

[4] Á. BARICZ, Geometric properties of generalized Bessel functions of complex order, Mathematica 4 (71) (2006), 13-18.

[5] Á. BARICZ, Generalized Bessel functions of the first kind, Lecture Notes in Mathematics, vol. 1994. Springer-Verlag, Berlin, 2010.

[6] Á. BARICZ AND S. Ponnus Amy, Starlikeness and convexity of generalized Bessel functions, Integral Transforms Spec. Funct. 21 (9-10) (2010), 641-653.

[7] Á. BARICZ AND R. SzÁsZ, The radius of convexity of normalized Bessel functions of the first kind, Anal. Appl. (Singap.) 12, 5 (2014), 485-509.

[8] R. K. BROwn, Univalence of Bessel functions, Proc. Amer. Math. Soc. 11, 2 (1960), 278-283.

[9] A. W. Goodman, Univalent functions. Vol. I \& II, Mariner, Tampa, FL, 1983.

[10] W. JANOWSKI, Some extremal problems for certain families of analytic function I, Ann. Polon. Math. 28 (1973), 297-326.

[11] E. O. A. Kreyszig And J. Todd, The radius of univalence of Bessel functions I, Notices Amer. Math. Soc. 5 (1958), 664.

[12] C. P. MCCARTY, Functions with real part greater than $\alpha$, Proc. Amer. Math. Soc. 35 (1972), $211-$ 216.

[13] S. S. Miller AND P. T. Mocanu, Univalence of Gaussian and confluent hypergeometric functions, Proc. Amer. Math. Soc. 110, 2 (1990), 333-342.

[14] S. S. Miller AND P. T. Mocanu, Differential subordinations and inequalities in the complex plane, J. Differential Equations 67, 2 (1987), 199-211.

[15] S. S. Miller and P. T. Mocanu, Differential subordinations, Monographs and Textbooks in Pure and Applied Mathematics, 225, Dekker, New York, 2000.

[16] F. W. J. Olver, D. W. Lozier, R. F. Boisvert, C. W. Clark (Eds.), NIST Handbook of Mathematical Functions, Cambridge Univ. Press, Cambridge, 2010.

[17] S. Ponnus Amy AND M. VuORINEN, Univalence and convexity properties for confluent hypergeometric functions, Complex Variables Theory Appl. 36, 1 (1998), 73-97. 
[18] M. S. Robertson, Schlicht solutions of $W^{\prime \prime}+p W=0$, Trans. Amer. Math. Soc. 76 (1954), 254-274.

[19] St. RuscheweYh AND V. Singh, On the order of starlikeness of hypergeometric functions, J. Math. Anal. Appl. 113, 1 (1986), 1-11.

[20] V. Selinger, Geometric properties of normalized Bessel functions, Pure Math. Appl. 6, 2-3 (1995), 273-277.

[21] R. SZÁSZ AND P. A. KupÁn, About the univalence of the Bessel functions, Stud. Univ. Babeş-Bolyai Math. 54, 1 (2009), 127-132.

[22] N. M. Temme, Special functions, A Wiley-Interscience Publication, Wiley, New York, 1996. 